\title{
Computational Simulation for Concurrent Engineering of Aerospace Propulsion Systems
}

C.C. Chamis

National Aeronautics and Space Administration

Lewis Research Center

Cleveland, Ohio

and

S.N. Singhal

Sverdrup Technology, Inc.

Lewis Research Center Group

Brook Park, Ohio

Prepared for the

1992 American Institute of Aeronautics and Astronautics Aerospace Design Conference

Irvine, California, February 3-6, 1992 


\title{
COMPUTATIONAL SIMULATION FOR CONCURRENT ENGINEERING
}

\section{OF AEROSPACE PROPULSION SYSTEMS}

\author{
C.C. Chamis ${ }^{*}$ \\ National Aeronautics and Space Administration \\ Lewis Research Center \\ Cleveland, Ohio 44135 \\ and \\ S.N. Singhal ${ }^{* *}$ \\ Sverdrup Technology, Inc. \\ Lewis Research Center Group \\ Brook Park, Ohio 44142
}

\section{SUMMARY}

Results are summarized of an investigation to assess the infrastructure available and the technology readiness in order to develop computational simulation methods/software for concurrent engineering. These results demonstrate that development of computational simulation methods for concurrent engineering is timely. Extensive infrastructure, in terms of multi-discipline simulation, component-specific simulation, system simulators, fabrication process simulation, and simulation of uncertainties - fundamental to develop such methods, is available. An approach is recommended which can be used to develop computational simulation methods for concurrent engineering of propulsion systems and systems in general. Benefits and issues needing early attention in the development are outlined.

\section{INTRODUCTION}

Advanced structural systems in general and propulsion systems in particular are presently developed by a loosely integrated procedure where each participating discipline (research, design, analysis, fabrication, quality control/assurance, operation, and maintenance) performs its assigned task independently. This is often followed by manual iteration to establish interdisciplinary compatibility. The adequacy of the system is subsequently evaluated by extensive sub-component, component, and system tests. This process has produced aircraft propulsion systems with outstanding reliability and durability. The process, however, is costly and lengthy. A continuing challenge in a competitive environment is to achieve the same results in less time, more efficiently, and in a manner which allows for easier incorporation of new technology with equal confidence for safety.

A proposed alternative is a formal framework in the form of an integrated software system where all the participating engineering disciplines, mentioned previously, interact continuously (concurrent engineering) through discipline-dedicated work stations using a common database. Relevant discussions appear in recent proceedings of a workshop sponsored by NASA Headquarters (ref. 1). The discussions in this workshop focused on a feasibility investigation of the methodology readiness in order to undertake the development of Computational Simulation for Concurrent Engineering (CSCE). An important part of the investigation included available methodology infrastructure of (1) single and multi-discipline computational simulation and

\footnotetext{
${ }^{*}$ Senior Aerospace Scientist, Structures Division.

${ }^{* *}$ Section Supervisor, Structural Mechanics Group.
} 
(2) integrated computer programs to computationally simulate design/analysis/fabrication/processing of components, subcomponents and assemblies. An expected result from the investigation was that ComputerAided Design (CAD) and Computer-Aided Manufacturing (CAM) concepts can beaugmented and combined with discipline-specific computational simulation methods. The objective of this paper is to outline a computational simulation approach for the multi-disciplinary procedure through which propulsion systems can be conceived, designed, developed, installed, operated, and maintained.

\section{CONCURRENT ENGINEERING - WHAT? WHY? HOW?}

In this section we describe: (1) what is meant by concurrent engineering, (2) why there is a current awareness/emphasis on concurrent engineering and, (3) how may concurrent engineering be implemented and/or practiced. The description is by no means inclusive. However, it represents one interpretation and an assessment of these three important aspects of the subject.

1. What is Concurrent Engineering? In the simplest sense, concurrent engineering is the coupling of CAD/CAM - Computer Aided Design (CAD) with Computer Aided Manufacturing (CAM). It is a natural evolution since the results of computer aided design of a component in digitized form can readily be transferred to computer controlled machines to manufacture that component. This coupling also provides feedback to produce a design which is compatible with the machines. CAD/CAM provided the mechanism for designers and fabricators to participate concurrently (simultaneous feedback) to assure that the low cost design is also adaptable to low cost manufacturing. One perception is that concurrent engineering is the formation of tiger teams with experts from each discipline (design, manufacturing, quality assurance, others) which meet and brainstorm concurrently. This type of concurrent engineering is neither new (as anyone who has participated in proposal preparations and in new product development can readily attest), nor does it provide for the instantaneous feedback necessary for implementation of the discipline tasks. The proposed view of concurrent engineering is the process through which all participating disciplines interact concurrently "cradle to grave" through a common database to develop a low-cost, durable, reliable, and "maintenance-free" product in the shortest time possible.

2. Why Concurrent Engineering? Simply, because in a highly competitive world market, continuous improvements in the efficiency of the development cycle are necessary. An example for the development of a liquid propulsion system is schematically depicted in figure 1 (ref. 1). The approach shown is the traditional building block approach. As indicated in the figure, this approach is test intensive and, therefore, is time consuming. Though the traditional approach works and has resulted in successful and safe propulsion systems as previously mentioned, it can be improved by judicious use of recent developments in computational simulation methods and in computer hardware systems.

3. How is Concurrent Engineering Implemented and/or Practiced? The state-of-the-art of concurrent engineering may be summarized as follows (ref. 1): (1) mission requirements are used to identify an initial design concept, the participating engineering disciplines and their respective tasks; (2) each discipline performs its task independently, often leaving unresolved contradictory interdisciplinary requirements; (3) discipline participants in overlapping tasks interact with each other on as-needed basis to assess compatibility; (4) interdiscipline interactions are usually kept to a minimum which may result in overly conservative designs; (5) interfacing difficulties/anomalies are ironed out during fabrication and during development (test-stand) testing; (6) modifications to remedy shortcomings identified during teststand or during operations are directed to and resolved by the specific discipline with seldom feedback to other participating disciplines; (7) no consideration is usually given to customers' feedback as a concurrent participant until the product is already on the market. 


\section{ASSESSMENT OF AVAILABLE INFRASTRUCTURE AND METHODOLOGY READINESS}

It must be clear by now, that the state-of-the art of Concurrent Engineering is a complex and ad hoc process. Its formal development must build on available infrastructure which is evolutionary and consists of discipline-task or component-specific simulation computer programs. Some of these computer programs (computational simulators) can be used to demonstrate in a limited way and on a specific case basis, that computational simulation of concurrent engineering is not only feasible but timely. The following examples are selected to illustrate this point.

1. Structural Tailoring of Engine Blades - The concept and representative results are shown in figure 2 (ref. 2). This type of computational simulation permits the design of a blade to meet system (engine) performance requirements (ROI - Return on Investment) at considerably reduced time. The design defines the blade in all its details with hot and cold configurations. These configurations can be electronically transferred to computer controlled machines to fabricate blades which match disk assembly requirements. In addition, structural performance-specific values, for variables such as frequencies, displacements, and cyclic strains, are available which can be used for accept/reject quality criteria for verification and for in-service health monitoring.

2. Structural Tailoring of Turboprops - The concept and results of this specific example are shown in figure 3 (ref. 3). The various participating disciplines are listed as well as tailored results of the multifacet design. The tailored design specified the internal construction and the external geometry of the turboprops. All the details are in computer files which can be transferred to the shop to fabricate the blade. The fabrication requirements were formally represented by suitable constraints for (1) type of composite and fiber volume ratio, (2) ply thickness and number of plies per node, (3) type of spar, (4) spar shape, (5) type of adhesive, (6) cavity geometry, (7) angle of sweep, (8) twist angle, (9) camber, and (10) airfoil geometry tolerances. Specific values of response variables are available which can be used to qualify, verify, and certify the turboprop. This specific example illustrates the multi-discipline infrastructure, beyond simple CAD/CAM that is needed to develop computational simulation of the concurrent engineering process.

3. Passive Damping - A closely related example to turboprop tailoring is the identification of passive damping characteristics in the adhesive to suppress unanticipated vibration excitations. The concept and typical results are shown in figure 4 . The damping characteristics to reduce vibration amplitudes by at least two orders of magnitude are quantified. Adhesives with these characteristics can be produced if not already available. The chemical process for producing such adhesives is another discipline which can be formalized and made a part of the participating disciplines of the Concurrent Engineering Simulation.

4. Engine Fan Blades Tailored for Ice Impact - The physics for this specific case are described schematically in figure 5 (ref 4). A block diagram of computer code to accomplish it is shown in figure 6. The multi-discipline concurrent interaction is identified by the radial lines. A blade internal configuration to effectively resist a specific size of a piece of ice is shown in figure 7. Local strains as functions of impact angle for general aviation aircraft forward speeds are shown in figure 8 . The internal construction conforms to input for easy fabrication and the local strains provide information for blade quality assurance, verification, and health monitoring.

5. Acoustic Fatigue - This specific example is selected to illustrate how discipline-specific computer codes can be used to design composite laminates for increased fatigue resistance. The problem simulated and the discipline-specific codes are shown in figure 9 (ref 5). The schematics indicated how each discipline-specific computer code is used. The results from this simulation are shown in figure 10. As can be seen, laminates can be selected to increase the acoustic fatigue resistance by two orders of magnitude. 
These laminate configurations with their respective fiber volume ratios can be readily made with routine fabrication methods.

6. Multi-Discipline Tailoring - A more sophisticated tailoring procedure is depicted schematically in figure 11 (in-house unpublished notes). The block diagram of the computer code is shown in figure 12. Typical results obtained are shown in figure 13. The schematics in figure 13 show the internal blade construction to achieve the desired results. As was mentioned previously, this information is available in files which are readily transferable to the shop to fabricate the blade with the specific internal construction. Again, fabrication tolerances are included as constraints on the thicknesses for the different layers and on the external blade geometry. These constraints assure that the fabricated blade will successfully pass all the design requirements.

7. Metal Matrix Laminate Tailoring - This example is selected to illustrate direct inclusion of fabrication process variables in the simulation. The general concept is illustrated schematically in figure 14 (ref. 6). The computer code to perform this simulation is shown schematically in figure 15 . Results for maximum in-plane loads are shown in figure 16. The fabrication process to achieve these results is shown in figure 17. Though the tensile load did not change, the pressure consolidation time was reduced by at least 30 percent. The procedure also found a processing history to increase the compressive strength by about 50 percent.

8. Laminate Tailoring to Maximize Bending Loads - This last example is similar to the previous one. It is selected to demonstrate that the design and the fabrication process can be concurrently tailored to maximize the bending load carrying capacity of the laminate. The results are shown in figure 18 (inhouse unpublished notes). Substantial increases in the bending load was achieved compared to the current process. The corresponding simulated fabrication process is shown in figure 19. The pressure history changes dramatically. The digital information for this history is in files which can readily be transferred to control the fabrication process to achieve it.

Collectively, these specific examples demonstrate that substantial infrastructure is available and evolving that is essential to develop methods to computationally simulate concurrent engineering of aerospace propulsion components.

\section{SYSTEM SIMULATORS}

The simulation methods for discipline-specific and/or component-specific tasks are integrated to simulate entire systems. These simulators are next to the last steps to develop computational simulators for Concurrent Engineering. Two such simulators are under development at Lewis Research Center for aeropropulsion systems. The first is an Engine Structures Computational Simulator (ESCS) (ref. 7) as shown in figure 20. The discipline modules logic flow block diagram is shown in figure 21 . This block diagram demonstrates the concurrent interaction among participating disciplines as the design process evolves from mission definition to display of the tailored structural system. The second is a Numerical Propulsion System Simulator (NPSS) (ref. 8). NPSS is a higher level simulator than ESCS and includes major modules from ESCS as a module as well as other comparable modules from other participating disciplines to simulate the entire system from inlet to exhaust as is summarized in figure 22 .

Both of these successively higher level simulators further demonstrate that concurrent multidiscipline interaction can be formalized and that computational simulation of concurrent engineering is very timely indeed. They also lead to the next level of simulation which is that for the vehicle as shown in figure 23. 


\section{ACCOUNTING FOR UNCERTAINTIES}

A very important part in the resulting system/product of concurrent engineering is an accurate assessment of the product's reliability and risk. Simulation of product reliability and risk is most effectively performed by probabilistic methods. Over the past 8 years, Lewis Research Center has been developing Probabilistic Structural Analysis Methods (PSAM) for the Space Shuttle Main Engine (SSME) (ref. 9). The methodology has matured to the point where the uncertainties in load, structure, and material can be represented probabilistically. The corresponding uncertainties in the structural response can be quantified which can be subsequently used to assess component/system reliability and risk. The essence of the method is schematically illustrated in figure 24 (ref. 10). Typical results for an SSME blade are shown in figure 25. This approach can also be used to assess improvements in material processing versus probability of failure and cost as is shown in figure 26.

Accounting for uncertainties benefits the product/system development by: (1) minimizing the amount of testing required for qualification and certification, (2) relaxing fabrication tolerance of design parameters which have negligible influence on system performance and reliability, (3) widening the window for material acceptance criteria in situations where certain material characteristics are insignificant to product reliability, (4) bypassing the presently emerging concept of fuzzy theory application to product design - since quantification of uncertainties inherently defines the acceptable product performance range which fuzzy theory is supposed to determine by the use of a subjectively determined quality function. This function can be readily represented by a suitable segment of the cumulative probability distribution function. The methodology readiness to account for uncertainties, reliability and risk is sufficiently mature to be incorporated in computational simulation methods for concurrent engineering or component assemblies and even vehicles (fig. 27). In addition, PSAM can also be used to develop alternate models for material fabrication, assembly, quality, verification, and certification testing which will be required to implement computational simulation of concurrent engineering. Another feature is the sensitivities of design/processing/fabrication/etc. variables on desirable performance characteristics for specified reliability.

\section{COMPUTATIONAL SIMULATION FOR CONCURRENT ENGINEERING - NEEDS}

\section{IDENTIFICATION AND PROPOSED APPROACH}

Needs Identified - The following were identified during the feasibility investigation for the computational simulation of concurrent engineering (ref. 1). The state-of-the-art practice includes computational simulation of individual facets of concurrent engineering. It does not formalize the entire process. In order to fully implement computational simulation of the concurrent engineering process, the following need to be developed: (1) Coupled multi-disciplinary (from concept definition to retirement for-cause and even disposal) methods/software system for simultaneous interaction among participating disciplines through discipline-specific work stations - the discipline-specific and component-specific examples described previously are parts of these multi-disciplinary methods; (2) automated communication links to initiate and carry activities in each discipline task simultaneously, allowing uninterrupted interaction and feedback between tasks; (3) discipline-specific expert systems which permit nonexpert or neophyte participation; (4) smart neural nets for information processing within the database and communication to and from the discipline work stations; (5) adaptive methods to continuously upgrade the database from updates in each discipline task as well as from new technologies/materials/other relevant inventions; (6) zooming methods to quickly and automatically focus on priority discipline tasks, problem areas, and strategic issues; (7) efficient and interactive multi-disciplinary graphic displays at all stages of the system development cycle; (8) methods to verify system in-service performance while ascertaining system reliability integrated from 
the reliabilities of the participating disciplines; and (9) software adaptable to various hardware platforms: serial, parallel processors, others.

Proposed Approach Plan - Based on the previous discussion, a plan for the proposed approach emerged and is described as follows: "Integrate software packages for the computational simulation of multi-disciplinary procedures through which propulsion structural systems are developed (conceived, designed, fabricated, verified, certified), installed and operated." A schematic of this proposed plan is shown in figure 28. The plan is intricate and closed looped. The multi-discipline facets are shown at the top; the concurrent engineering computational simulation is at the center; and the simulated system evolution is at the bottom. It is envisioned that this software system will consist of: (1) work station with discipline-specific modules, dedicated expert systems, and local databases, (2) a central executive module with a global database and with communication links for concurrent interaction with the multi-discipline work stations, (3) unsupervised-learning neural nets, (4) adaptive methods for condensing and incorporating information as the system evolves, (5) zooming methods, (6) graphic displays, and (7) computergenerated files for computer controlled fabrication machines. The software system can be readily verified, as it evolves by applying it to simulate the development experience of existing propulsion systems with flight service. It is believed that the simulation process can be performed within 12 months once the system is in place. Implementation of the system depends on the resources available. The authors recommend to start with a component first and then progressively evolve the computational simulation to represent the whole system.

Implementation and practicing of concurrent engineering requires a cultural change in the way we presently develop new products/systems. In a recent symposium (ref. 11), it was pointed out that: (1) concurrent engineering, as presently practiced, is hindered by cultural barriers and interpersonal conflicts between the multi-discipline participants including procurement professionals. Computational simulation of concurrent engineering offers a quantifiable unbiased means to overcome such cultural barriers. For example, it would greatly reduce the cultural barriers by maximizing the flow of information/ interaction among the multi-discipline participants, while minimizing and possibly eliminating personal and parochial conflicts; (2) concurrent engineering requires more active participation of the management, at all levels and co-location of the participating discipline team members. Again, computational simulation provides a suitable and efficient vehicle to accommodate both of these, (3) concurrent engineering is hindered by frequent meetings. In the computational simulation alternative the participants interact concurrently through their discipline-specific workstations with no need for meetings thereby resulting in more effective use of engineering effort. Another significant roadblock is the management of the tremendous amount of information generated throughout the product development cycle. The computational simulation of concurrent engineering provides efficient management of the evolving information for instantaneous feedback and simultaneous improvements.

As a part of any implementation plan, simulation models for material processing, fabrication process, quality assurance, total quality and system risk management need be available. If not, these should be developed up front since simulation models (of one form or another) are available for the other participating disciplines. Another important aspect is the hardware. In preparing this report, it was tacitly assumed that the hardware will be available. Obviously, the hardware needs to be configured for specific implementations. A recent issue of "Computer-Aided Engineering" (12/91) is devoted to available hard-ware for CAD/CAM.

\section{SUMMARY OF RESULTS}

Computational simulation methods/software for concurrent engineering to be effective must include the following as a minimum: (1) workstations with discipline-specific modules, dedicated expert systems, 
and local databases, (2) a central executive module with a global database and with communication links for concurrent interaction with the multi-discipline work stations, (3) unsupervised-learning neural nets, (4) adaptive methods for condensing and incorporating information as the system evolves, (5) zooming methods, (6) graphic displays, and (7) computer-generated files for computer controlled fabricating machines. The software system can be readily verified, as it evolves by applying it to simulate the development experience from previous/current propulsion systems with flight service. The technology readiness to develop computational simulation methods for concurrent engineering is assessed in terms of infrastructure, system simulators, and accounting for uncertainties. Select examples for each of these are included to demonstrate that the infrastructure (methodology readiness) is available and the development of computational simulation methods for concurrent engineering is timely.

\section{REFERENCES}

1. Chamis, C.C.: Concurrent Engineering, invited presentation for the Space Transportation Propulsion Technology Symposium, Penn State University, June 25-29, 1990.

2. Brown, K.W., Pratt, T.K. and Chamis, C.C.: Structural Tailoring of Engine Blades, AIAA/ASME/AHS, 24th Structures, Structural Dynamics and Materials Conference, 1983.

3. Brown, K.: Structural Tailoring of Advanced Turboprops (STAT), United Technologies Corp., Pratt \& Whitney, 1988.

4. Reddy, E.S., Abumeri, G.H., Chamis, C.C., and Murthy, P.L.N.: Analysis of Aircraft Engine Blade Subject to Ice Impact, invited presentation at Ninth DOD/NASA/FAA Conference, Lake Tahoe, November 4-7, 1991.

5. Singhal, S.N., Murthy, P.L.N., Chamis, C.C., Nagpal, V.R., and Sutjahjo, E.: Computational Simulation of Acoustic Fatigue for Hot Composite Structures, NASA TM-104379, April 1991.

6. Morel, M., Saravanos, D.A., and Chamis, C.C.: Concurrent Micromechanical Tailoring and Fabrication Process Optimization for Metal-Matrix Composites, NASA TM-103670, November 1990.

7. Chamis, C.C.: Computational Structural Mechanics for Engine Structures, NASA TM-102119, April 1989.

8. Nichols, L.D., Chamis, C.C.: Numerical Propulsion System Simulation: An Interdisciplinary Approach, NASA TM-105181, September 1991.

9. Chamis, C.C.: Probabilistic Structural Analysis Methods for Space Propulsion System Components, NASA TM-88861, June 1986.

10. Chamis, C.C. and Murthy, P.L.N.: Probabilistic Composite Analysis, Preprint for First NASA Advanced Composite Technology (ACT) Conference, October 30-November 1, 1990.

11. Anon. The Management Symposium on Concurrent Engineering, by Swanson Analysis Systems, Inc., May 21, 1991, Pittsburgh, PA. 
Figure 1

LIQUID ROCKET PROPULSION

CURRENT DEVELOPMENT APPROACH

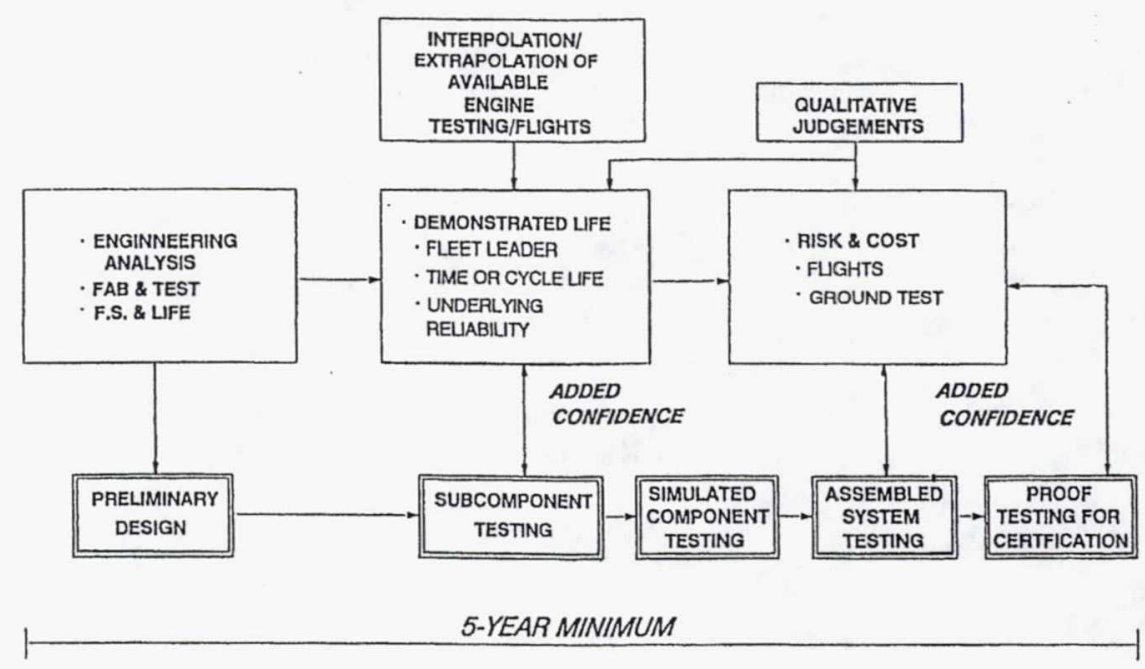

Figure 2

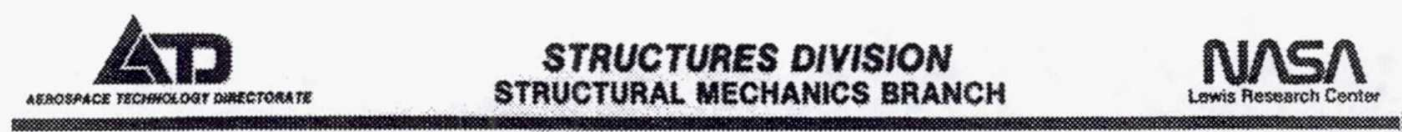

STAEBL - - STRUCTURAL TAILORING OF ENGINE BLADES
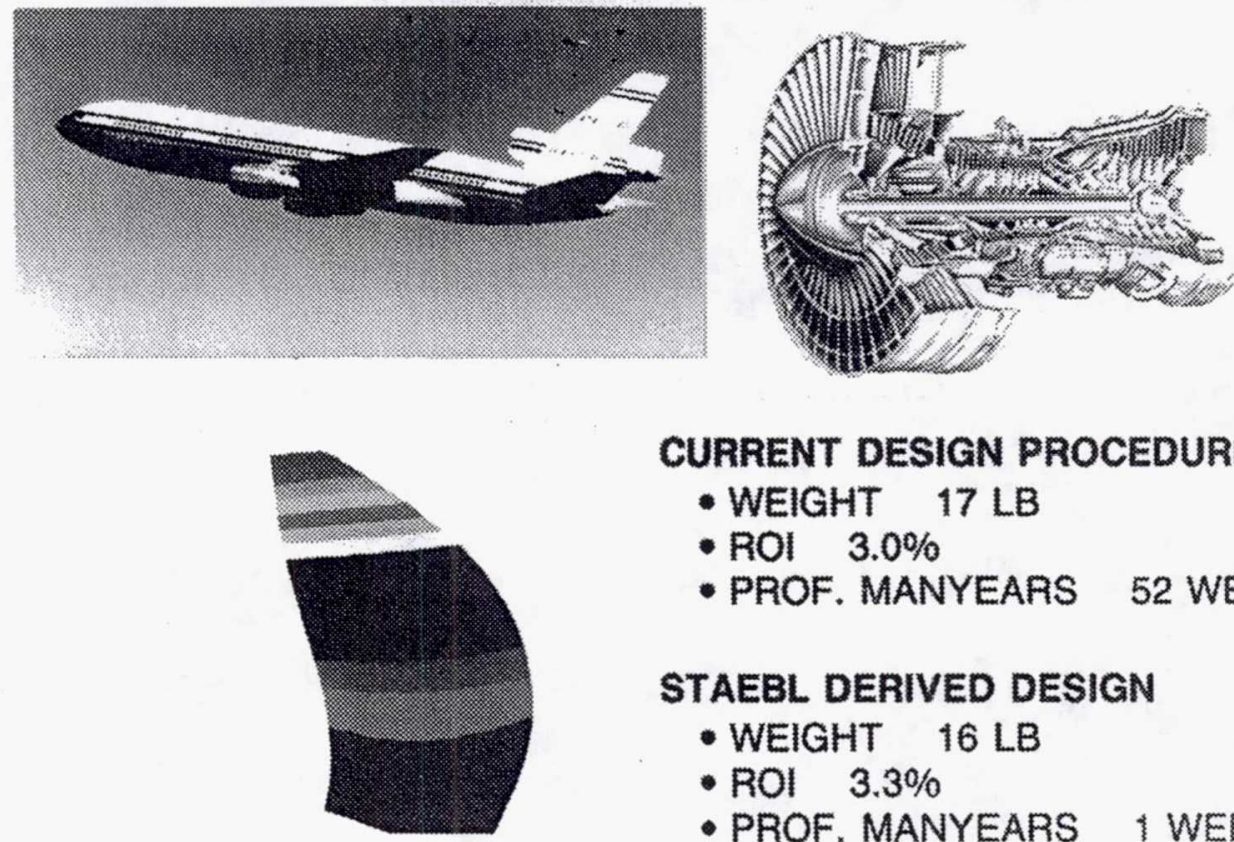

CURRENT DESIGN PROCEDURES

- WEIGHT $17 \mathrm{LB}$

- ROI $3.0 \%$

- PROF. MANYEARS 52 WEEKS

STAEBL DERIVED DESIGN

- WEIGHT 16 LB

- ROI $3.3 \%$

- PROF. MANYEARS WEEK 


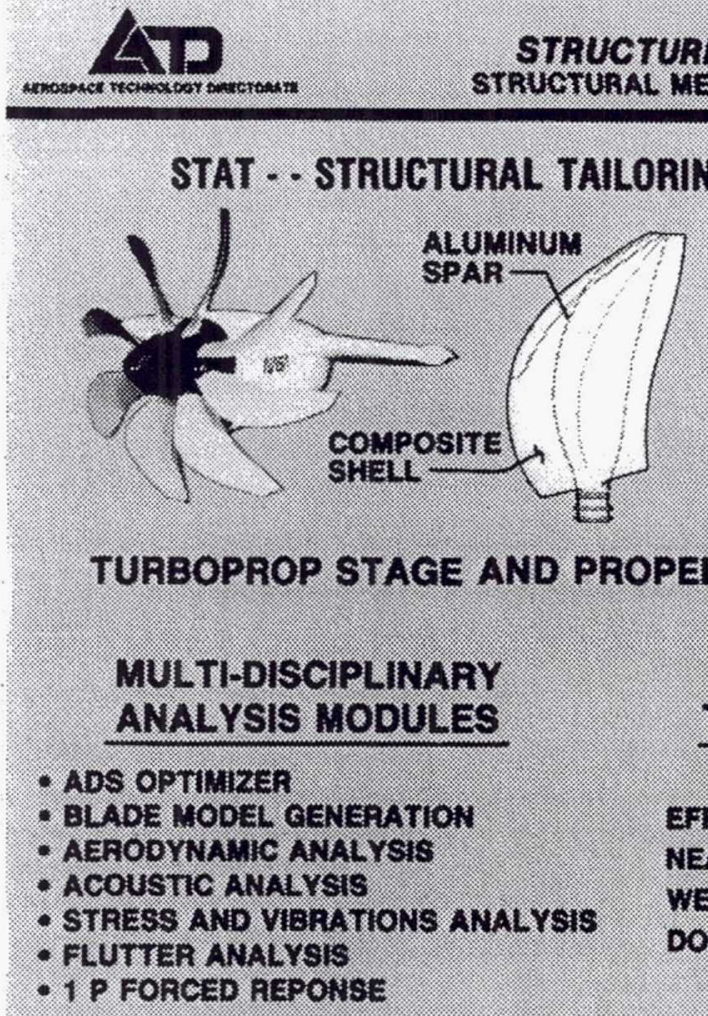

STRUCTURES DIVISTON

TRUUCTURAL MECHANLS BRANCH

\section{BLADE INTERNAL STRUCTURE}

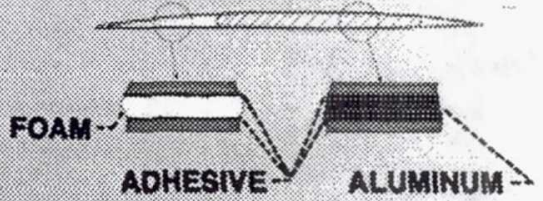

EFFICIENCY, * NEAH FEL NOISE, DB WEIGHT, LB Doc

\section{TYPICAL ANALYSIS RESULTS}

WITUAL FINAL

$82.86 \quad 83.17$

$\begin{array}{ll}143.8 & 137.3\end{array}$

$41.1 \quad 41.2$

$[-853-4.201]$

$20-87-24065$

Figure 4

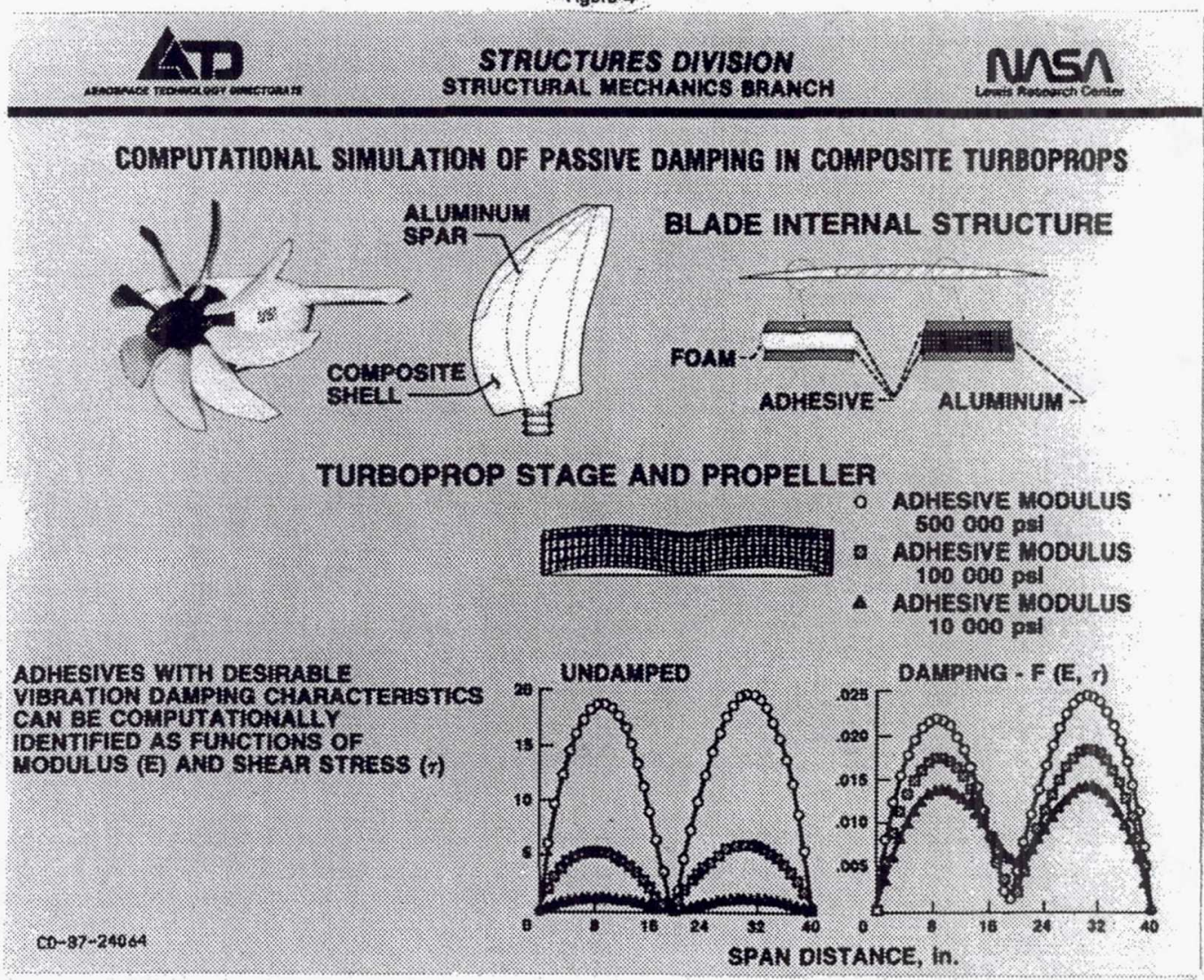


A Schematic of Ice Impact on an Engine Blade
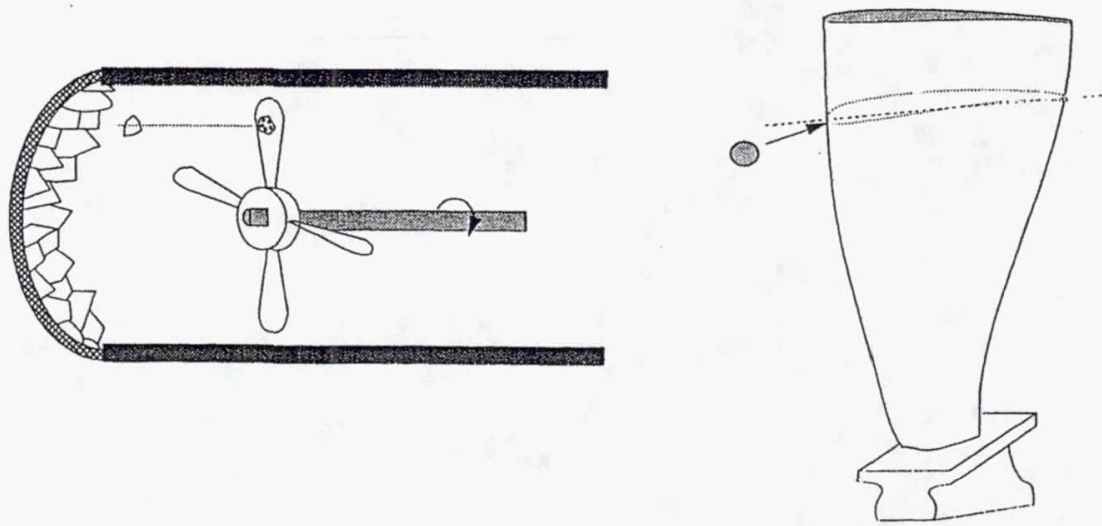

Figure 6

ANALYSIS CAPABILITIES OF ABIT CODE

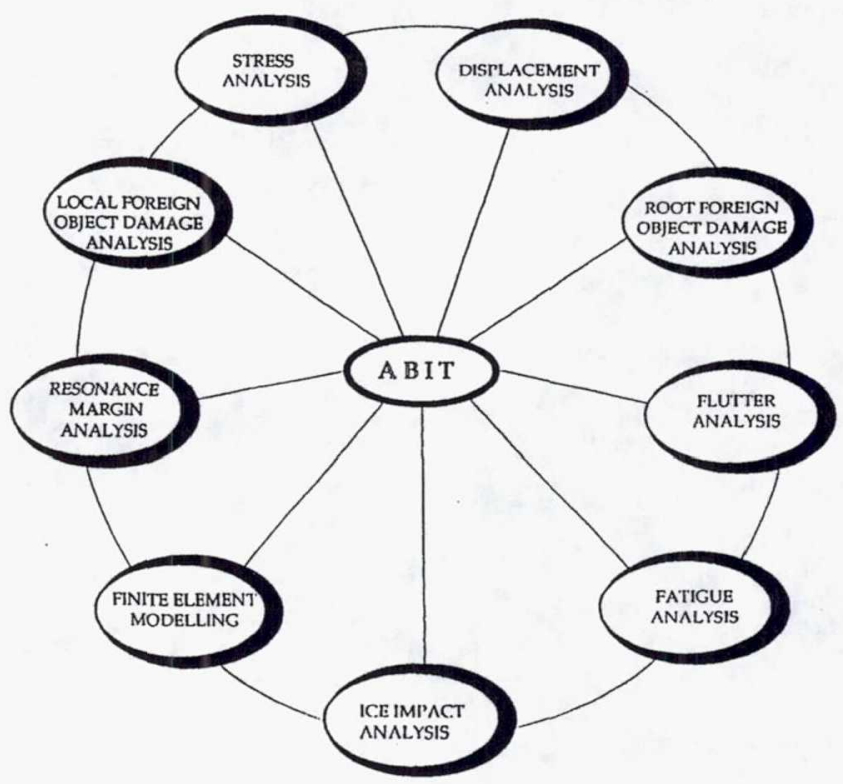




\section{Example Blade and Material Layer Configuration}
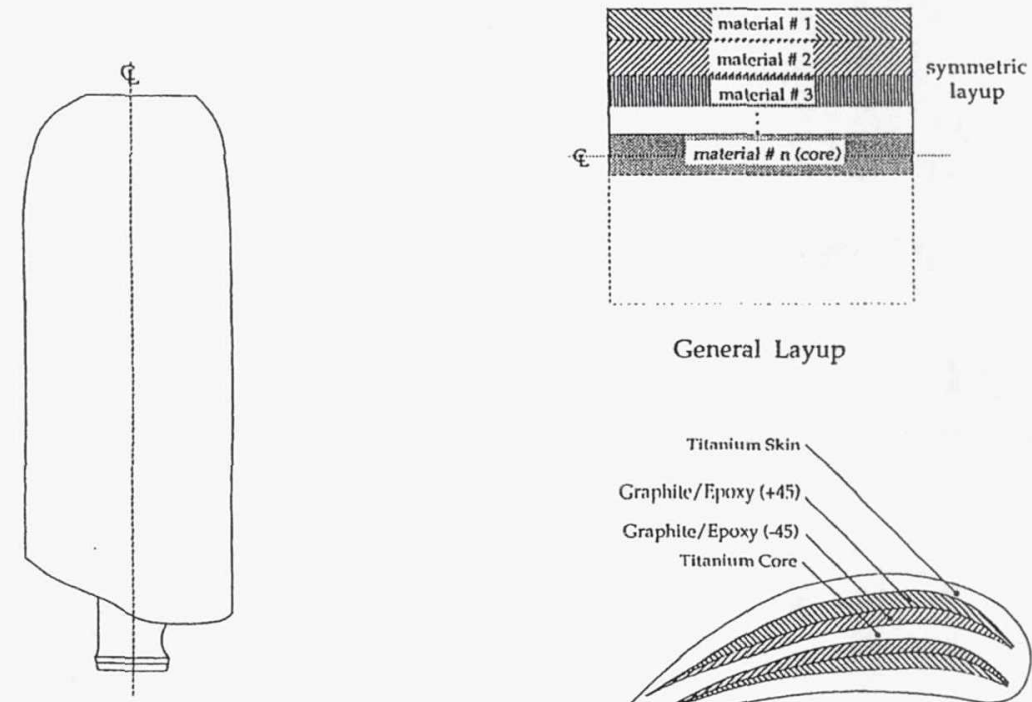

General Layup

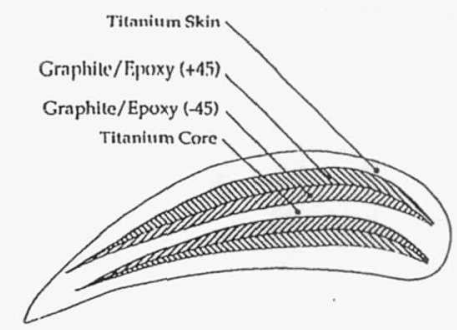

Planform of SR-2 Model Propfan Blade

Layup of the Unswept Blade Example

Figure 8

Variation of Average Leading Edge Strain and Impact Angle with Ice Speed

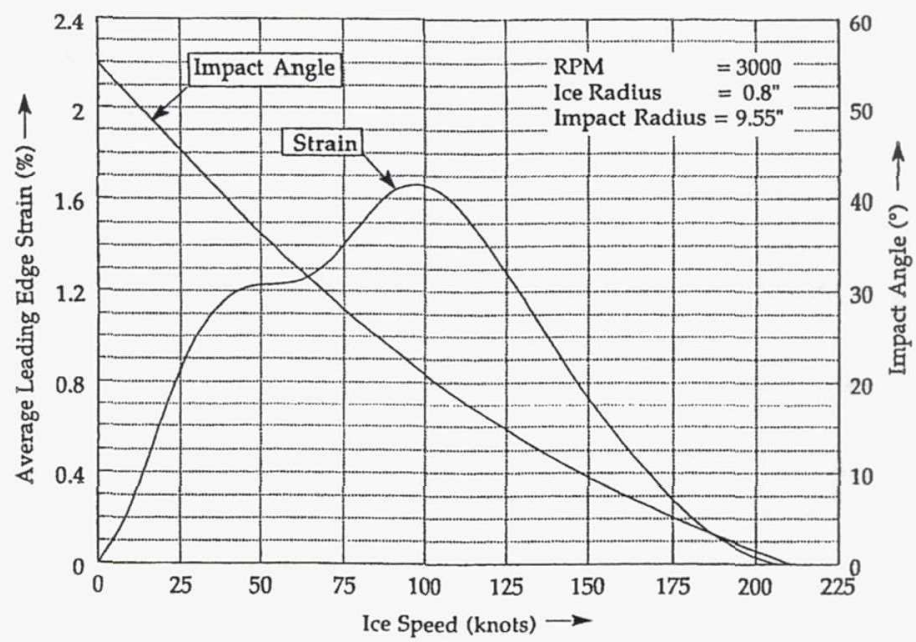


Figure 9

Computational Simulation of Acoustic Fatigue

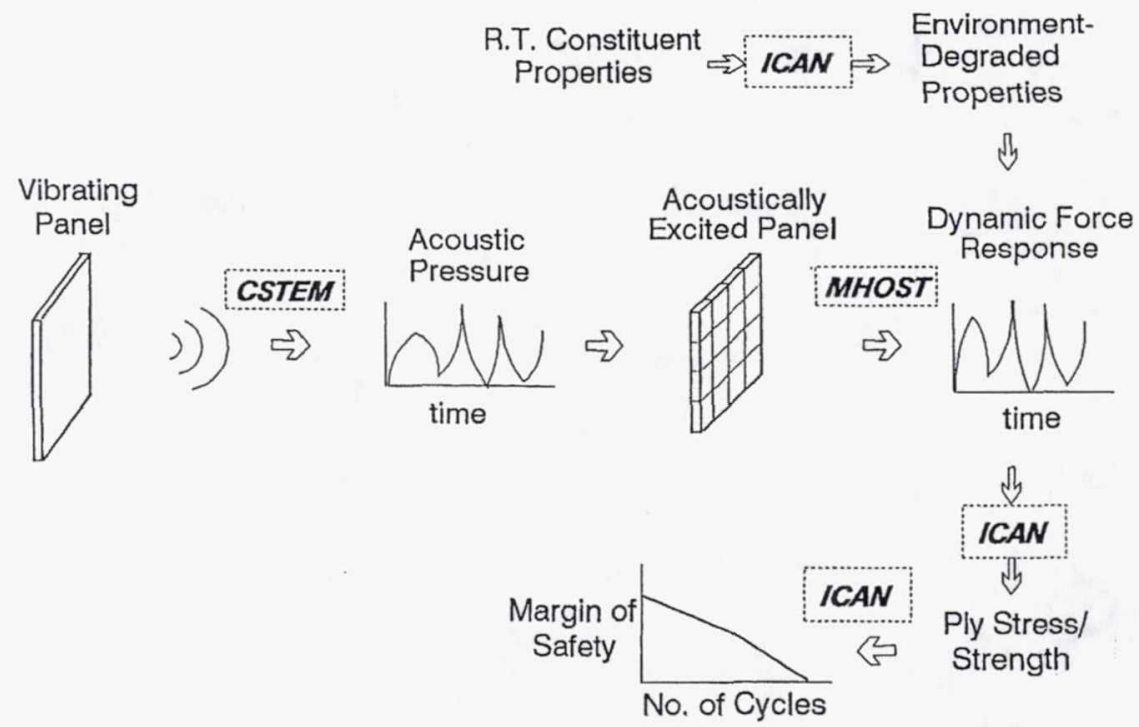

Figure 10

Demonstration: Effect of Configuration

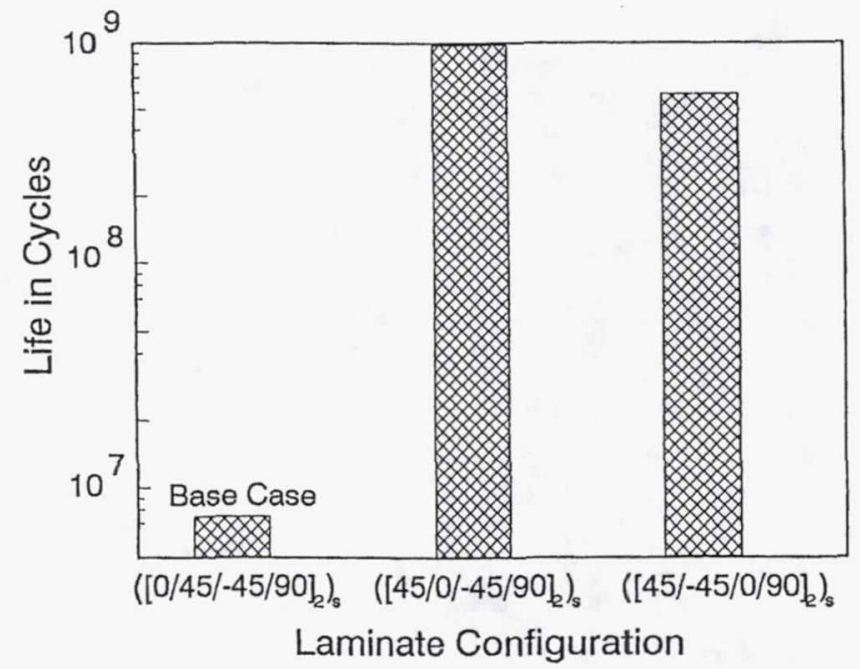




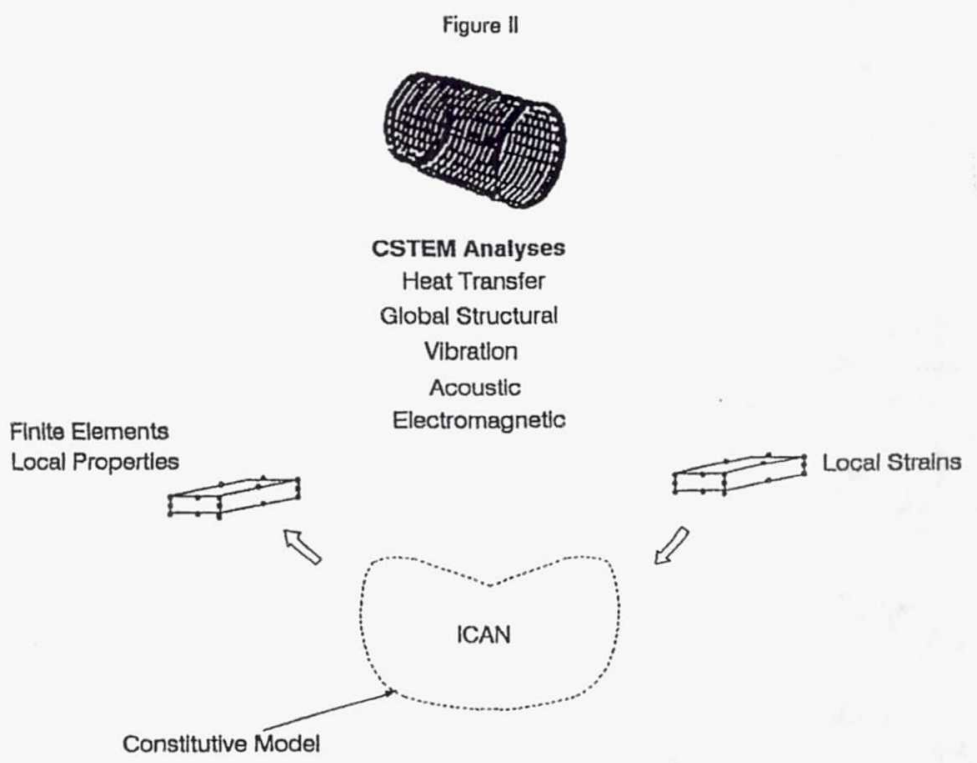

CSTEM Multi-disciplinary Analysis Capabilities Coupled with Integrated Composite Analysis (ICAN)

Figure 12

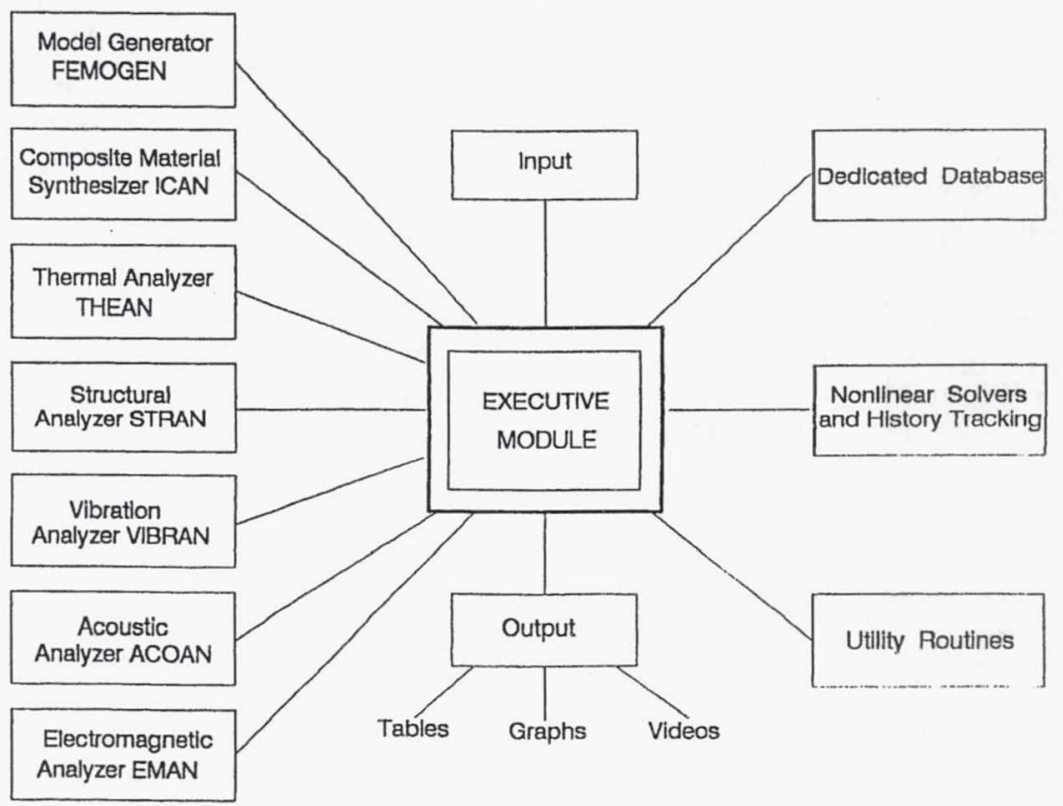

CSTEM Modular Structure 
Figure 13

MULTI-DISCIPLINARY TAILORING VIA CSTEM: SOME TYPICAL RESULTS Multi-material Multi-layered Fan Blade

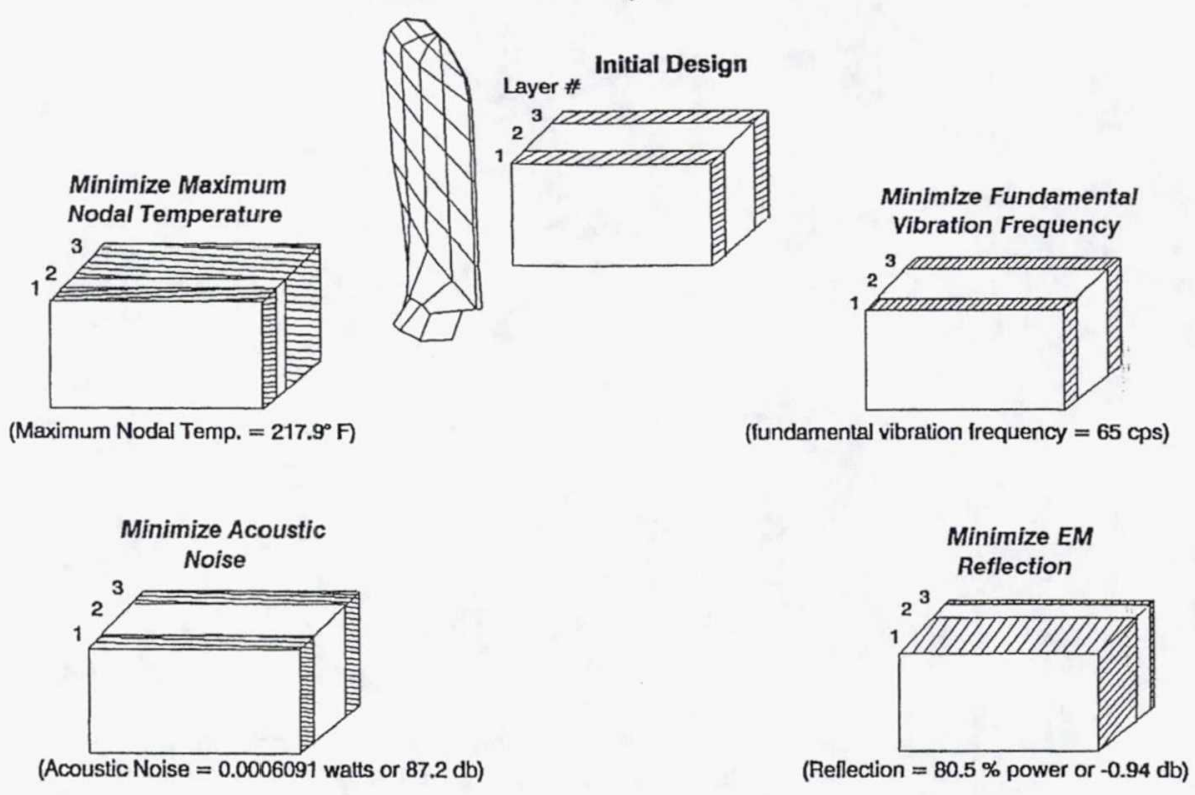

Figure 14

Typical Processing Cycle for Graphite/Copper
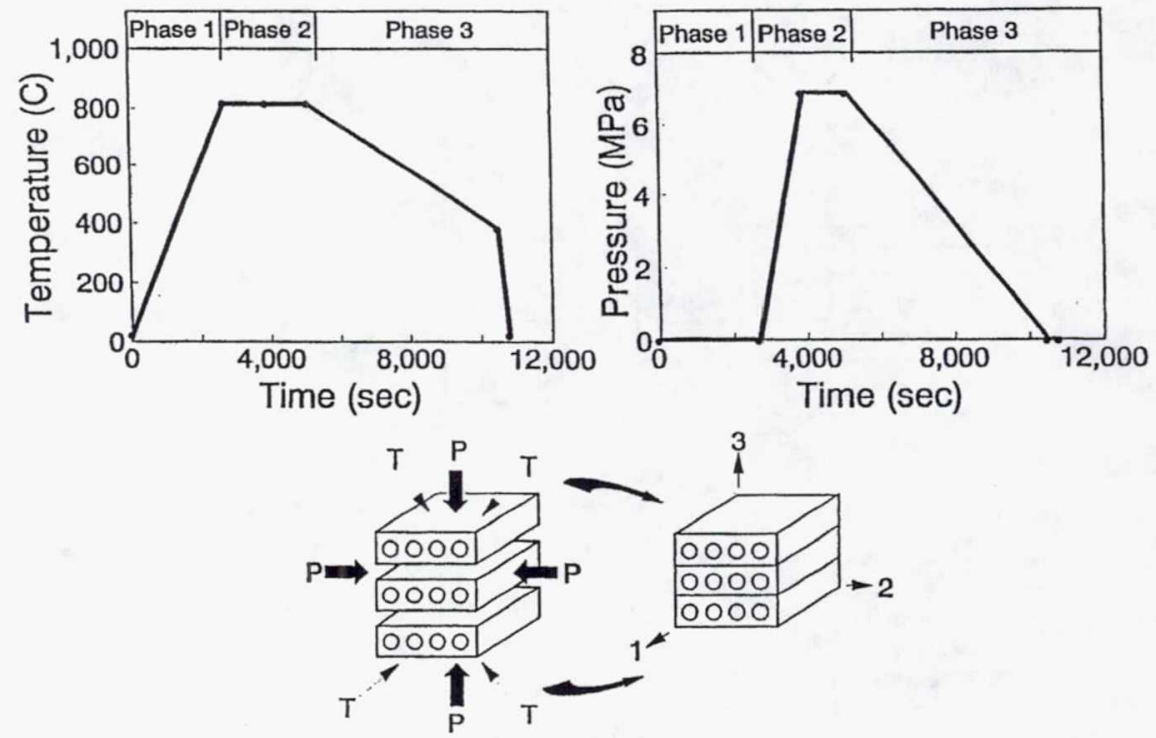


\section{Metal Matrix Laminate Tailoring (MMLT)}

Couple METCAN with Optimizer

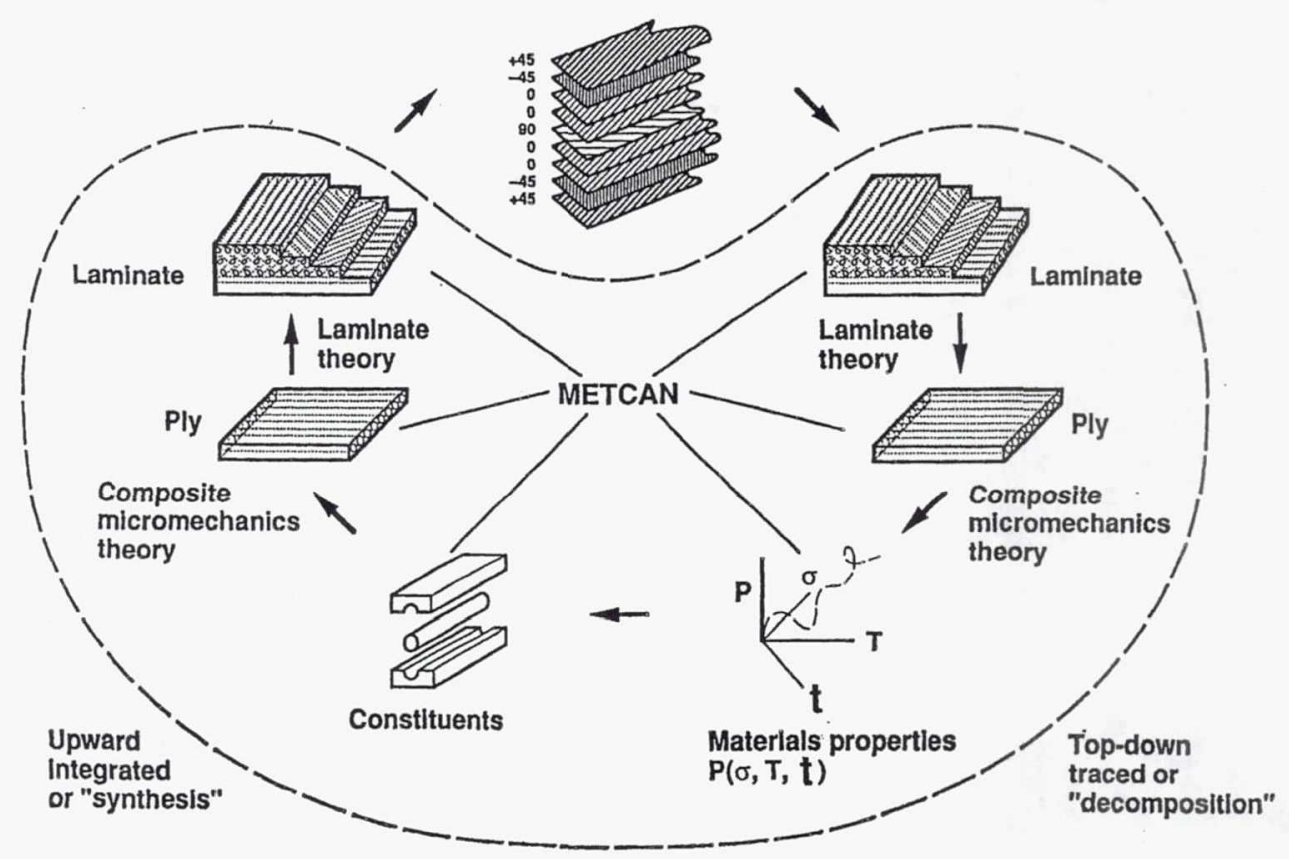

Figure 16

Fabrication Process Tailoring Influence on the Maximum In-Service Load for P100/Copper $[0 / 90]_{S}$ at $316^{\circ} \mathrm{C}$

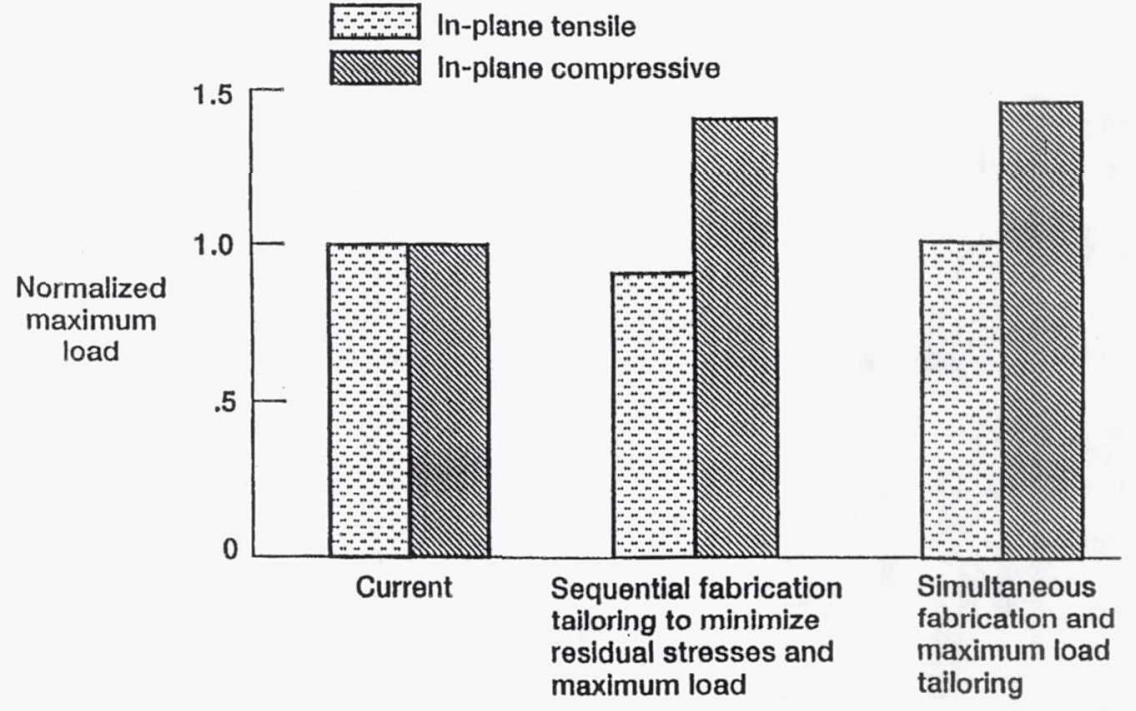


Figure 17

\section{Tailored Fabrication Process for $[0 / 90]_{S}$ Graphite/Copper by Different Objectives}

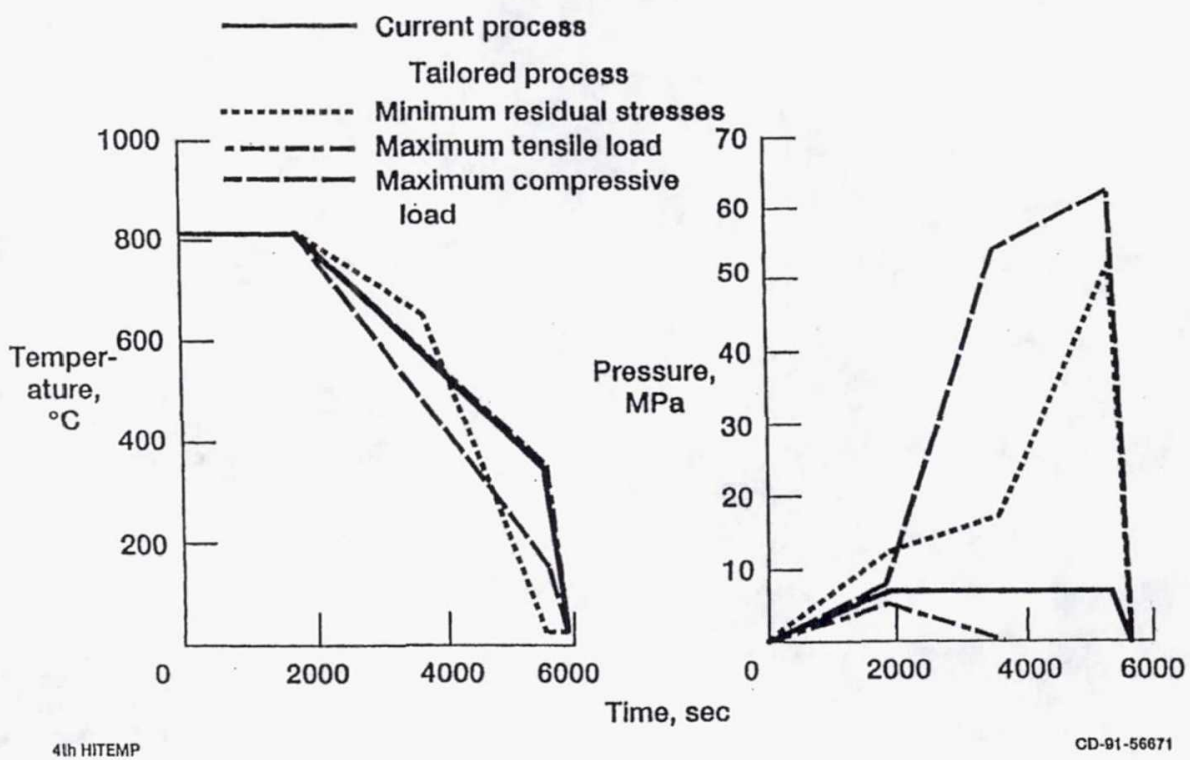

Figure 18

Biaxial Bending $\left(M_{x}=M_{y}\right)$

(0/90)s P100/Copper Laminate

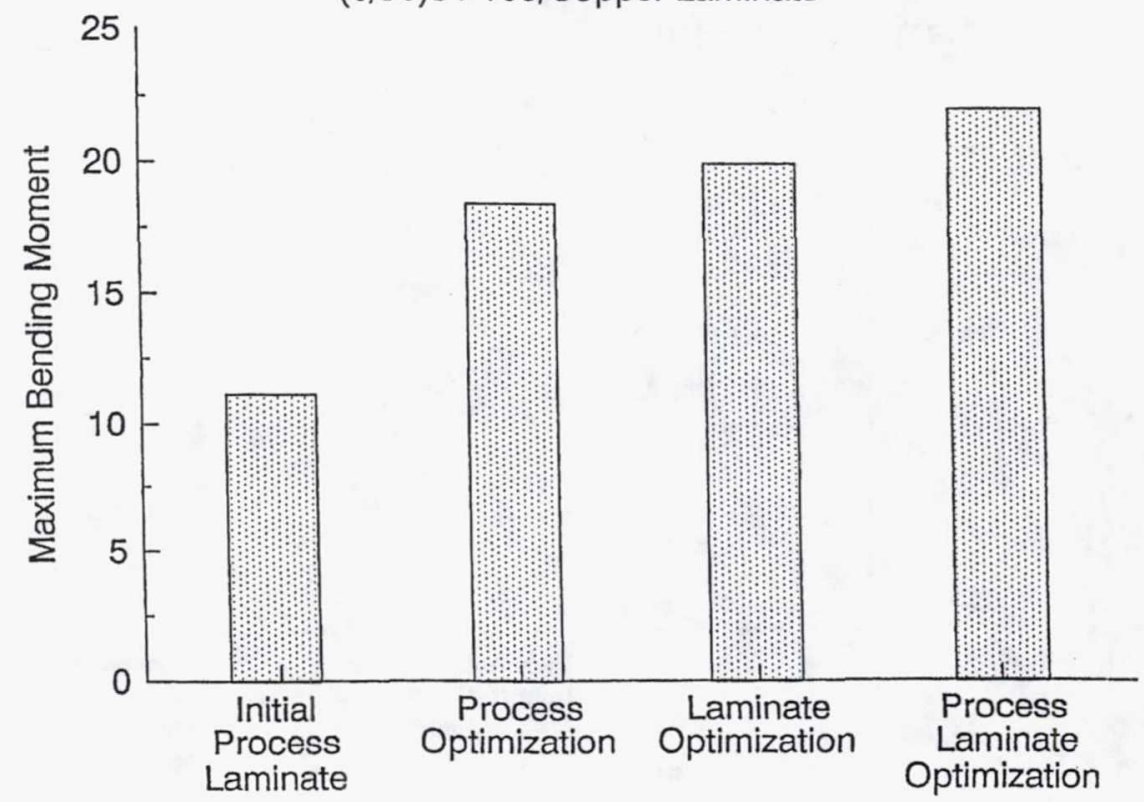


Figure 19

OPTIMUM FABRICATION PROCESSES

(0/90)S P100/COPPER IN BENDING
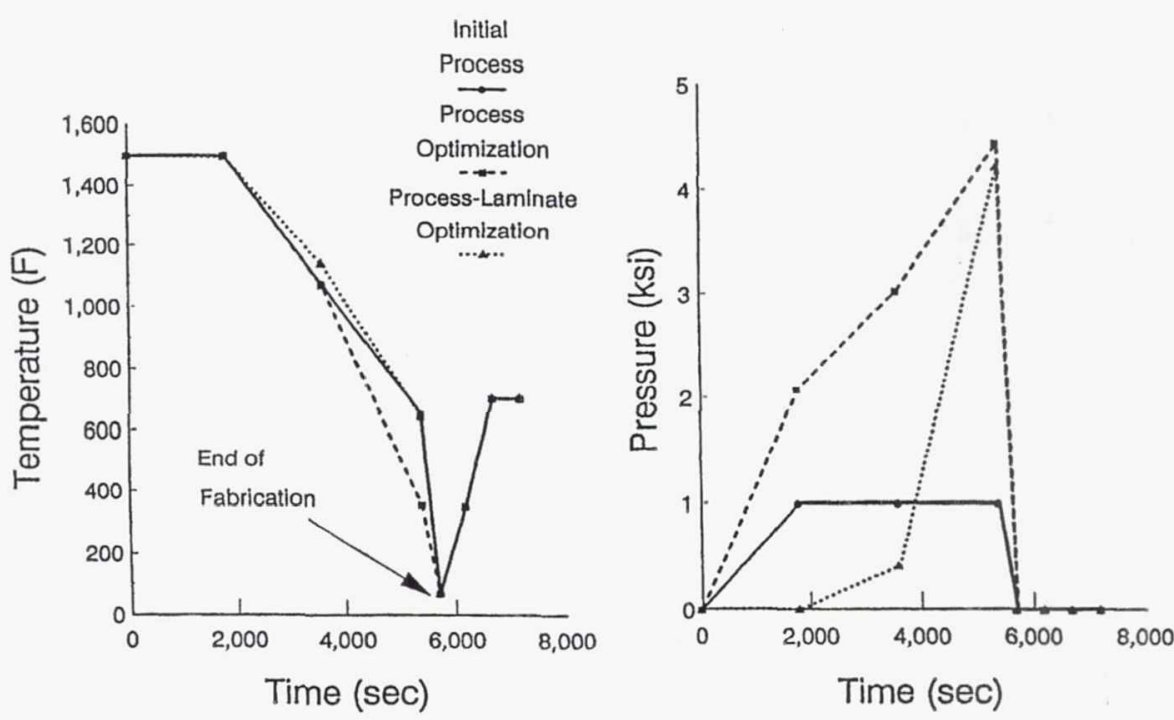

Figure 20

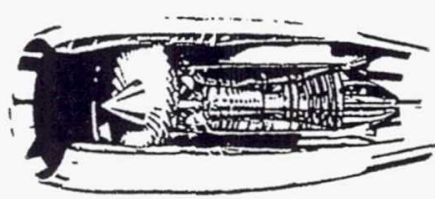

ENGINE

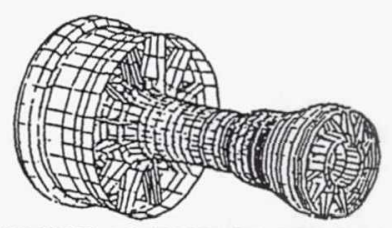

FINITE ELEMENT MODEL
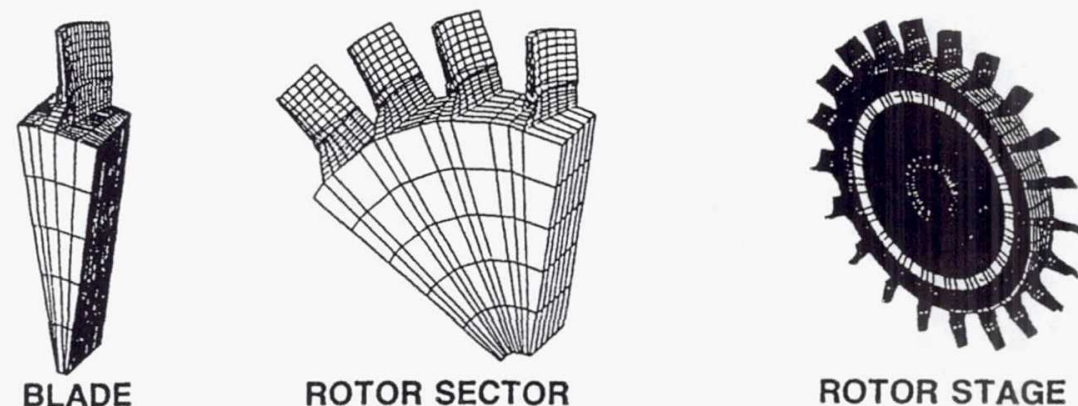

ROTOR STAGE

ENGINE STRUCTURES COMPUTATIONAL SIMULATOR. 
Figure 21

ENGINE STRUCTURES COMPUTATIONAL SIMULATOR (ESCS)

SIMULATION PROGRESSION DIAGRAM

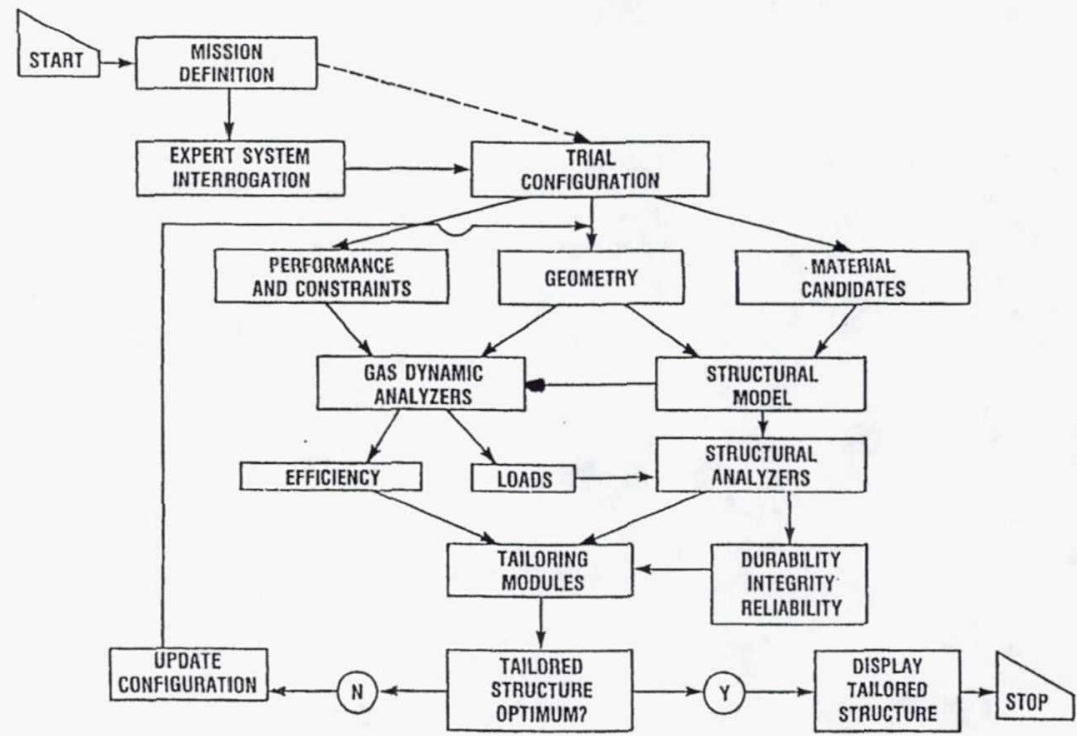

CD-89-40007

Figure 22

Nattonal Aoronuviltat and

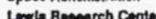

\section{NUMERICAL PROPULSION SYSTEM} SIMULATION (N.P.S.S.)

VALIDATED MODELS

- FLUID MECHANICS - HEAT TRANSFER - COMBUSTION - STRUCTURAL MECHANICS

MATERIALS

CONTROLS

RAPID COMPUTATION WITH KNOWN R N.P.S.S. N.P.S.S.
INTEGRATED INTERDISCIPLINARY
ANALYSIS AND ASSESSMENT OF

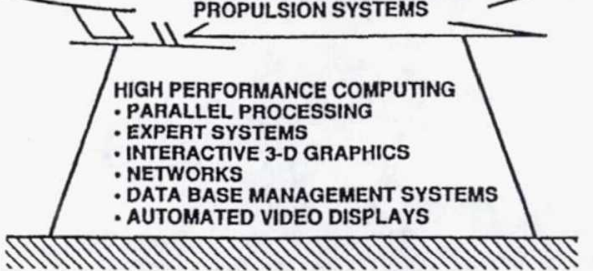

A NUMERICAL TEST CELL FOR AEROSPACE PROPULSION SYSTEMS 
Figure 23

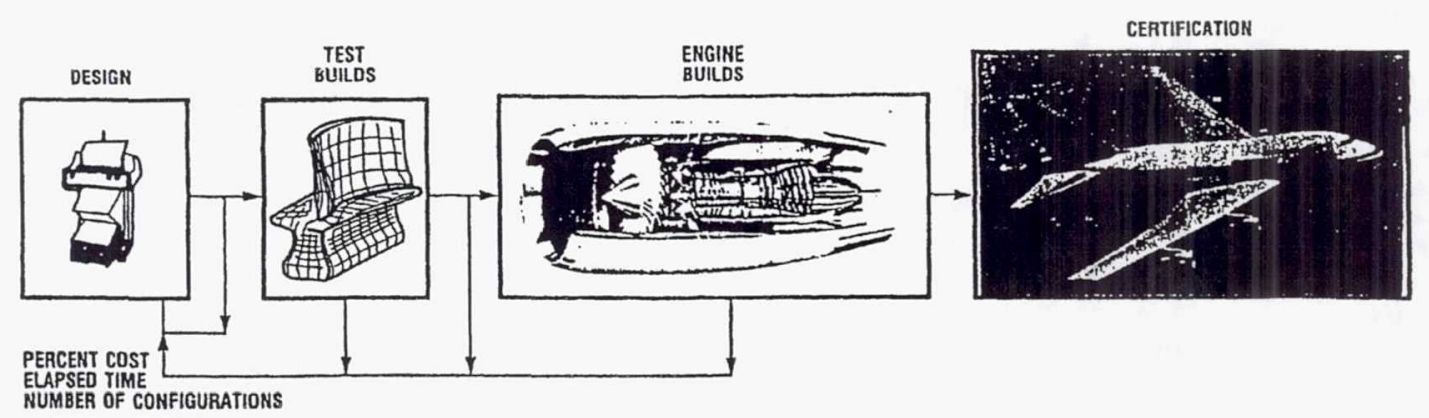

(A) CURRENT DEVELOPMENT METHOD.

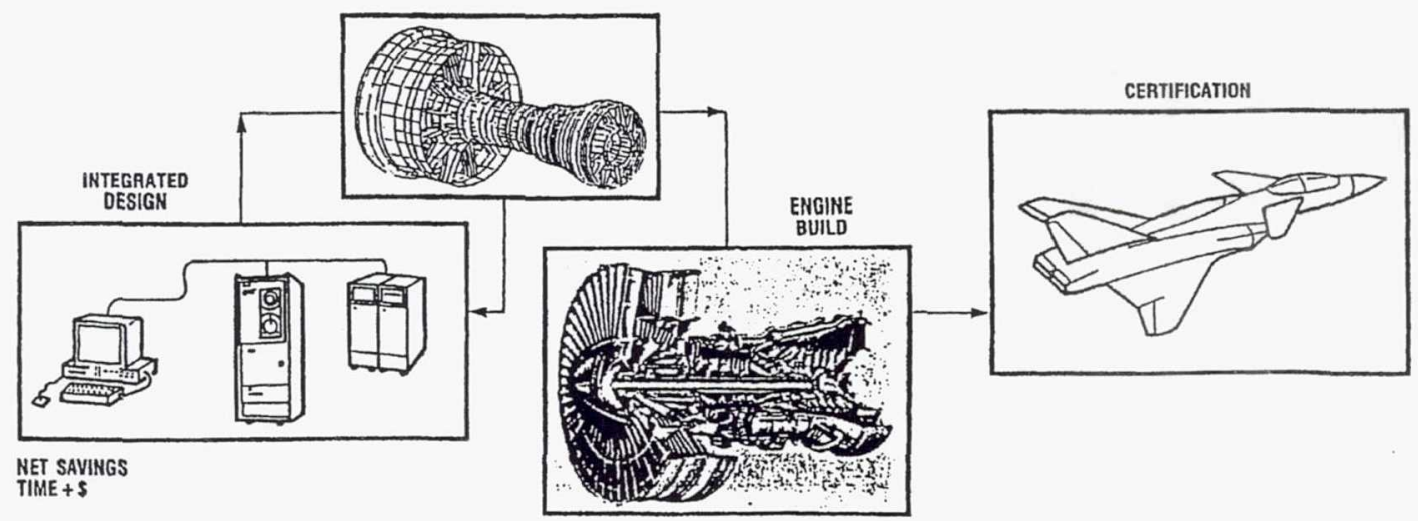

(B) COKPUTATIONAL SIMULATION METHOD.

PARALLEL BETWEEN CURRENT DEVELOPMENT AND COMPUTATIONAL SIMULATION METHODS.

\section{Figure 24 \\ PROBABILISTIC SIMULATION OF COMPONENT RELIABILITY USING CLS COUPLED WITH PSAM AND PMBM}

Probabilistic Load Description (QLS)

Probabilistic Structural -Analysis (PSAM-NESSUS)
Probabilistic Material

Behavior Models (
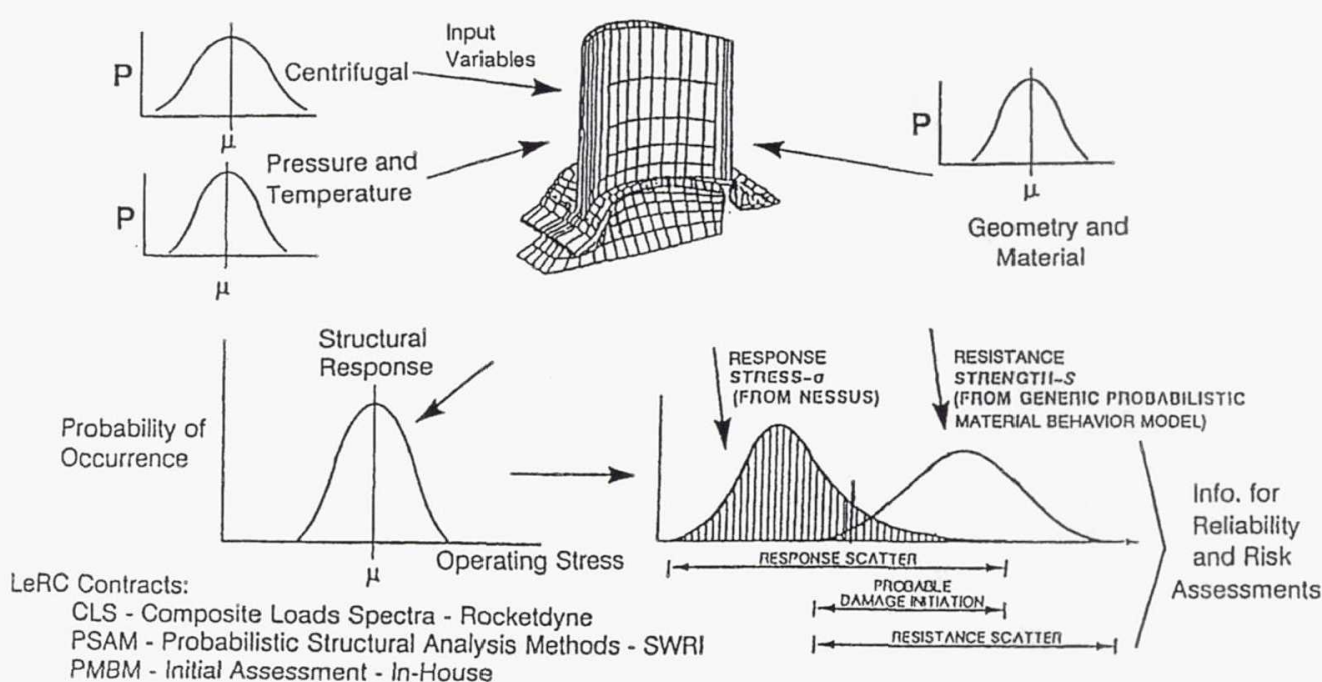

PSAM - Probabilistic Structural Analysis Methods - SWRI
PMBM - Initial Assessment - In-House 


\section{Figure 25 \\ PROBABILISTIC RISK-COST ASSESSMENT}

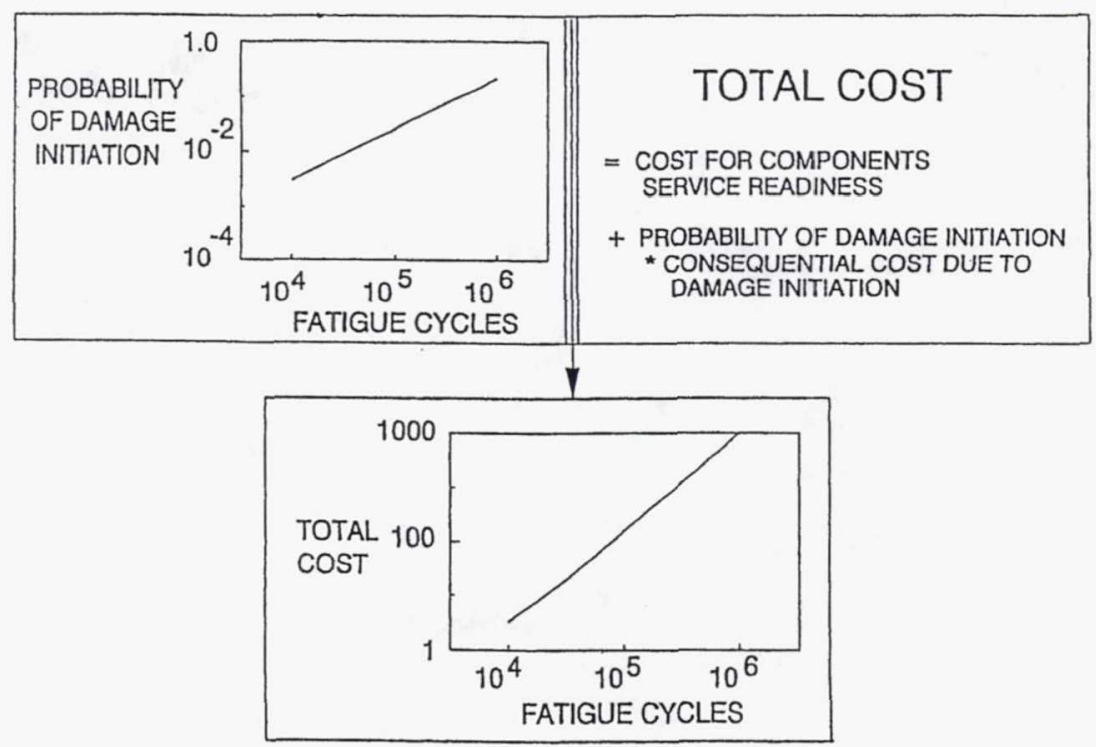

Figure 26

THE TOTAL COST TO IMPROVE THE STRUCTURAL RELIABILITY CAN BE QUANTIFIED IN TERMS OF QUALITY CONTROL (GIVEN MEAN STRENGTI)

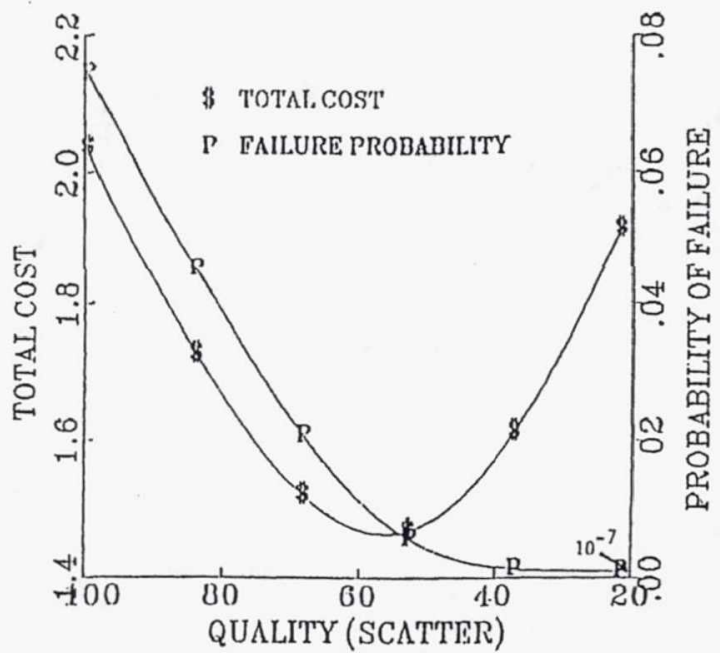




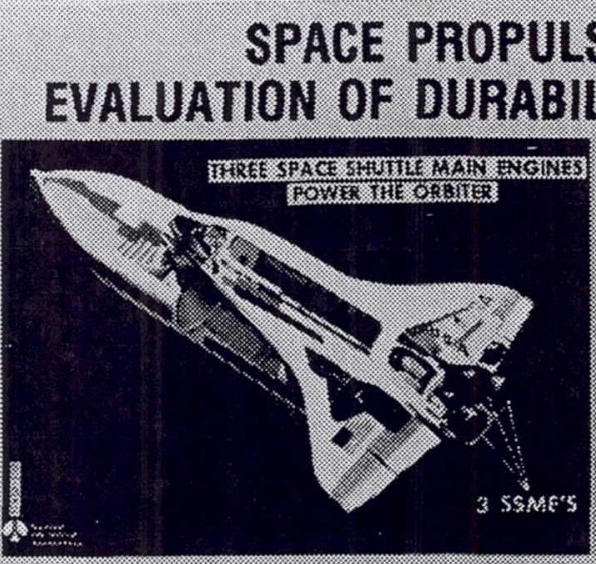

SPACE SWUTTLE

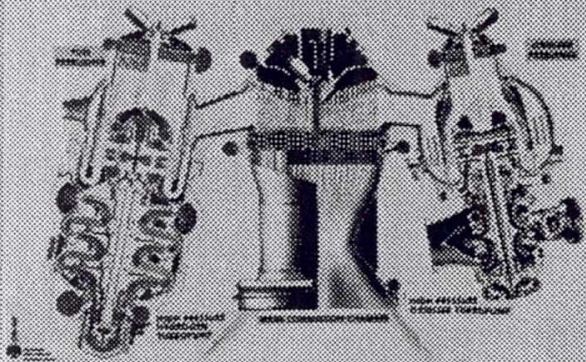

SPACE SHUTTLE MAIN ENCINE (SSWE) POWEA HEAB

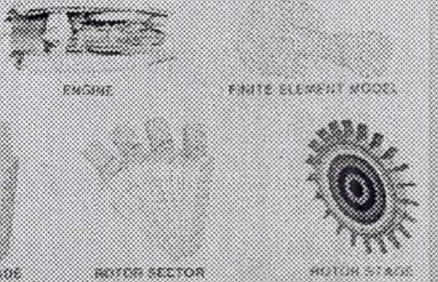

EUEHE STMUGTURES COMPUTATIONAL. SHEUULATOA FROM BLADE TO ROTOH TO EUTRE EWEIWE

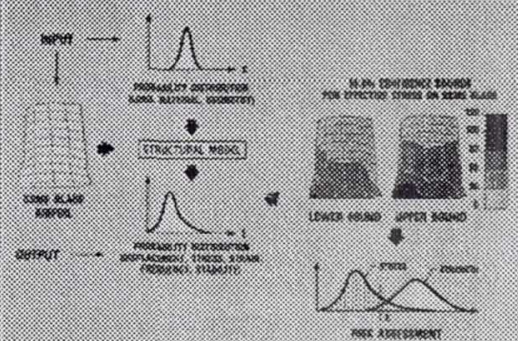

EVBINE STRUCTURES RELIABIUTY AWD RISK

Figure 28

PRPOSED PROGRAM: BLOCK DIAGRAM COMPUTATIONAL SIMULATION OF CONCURRENT ENGINEERING

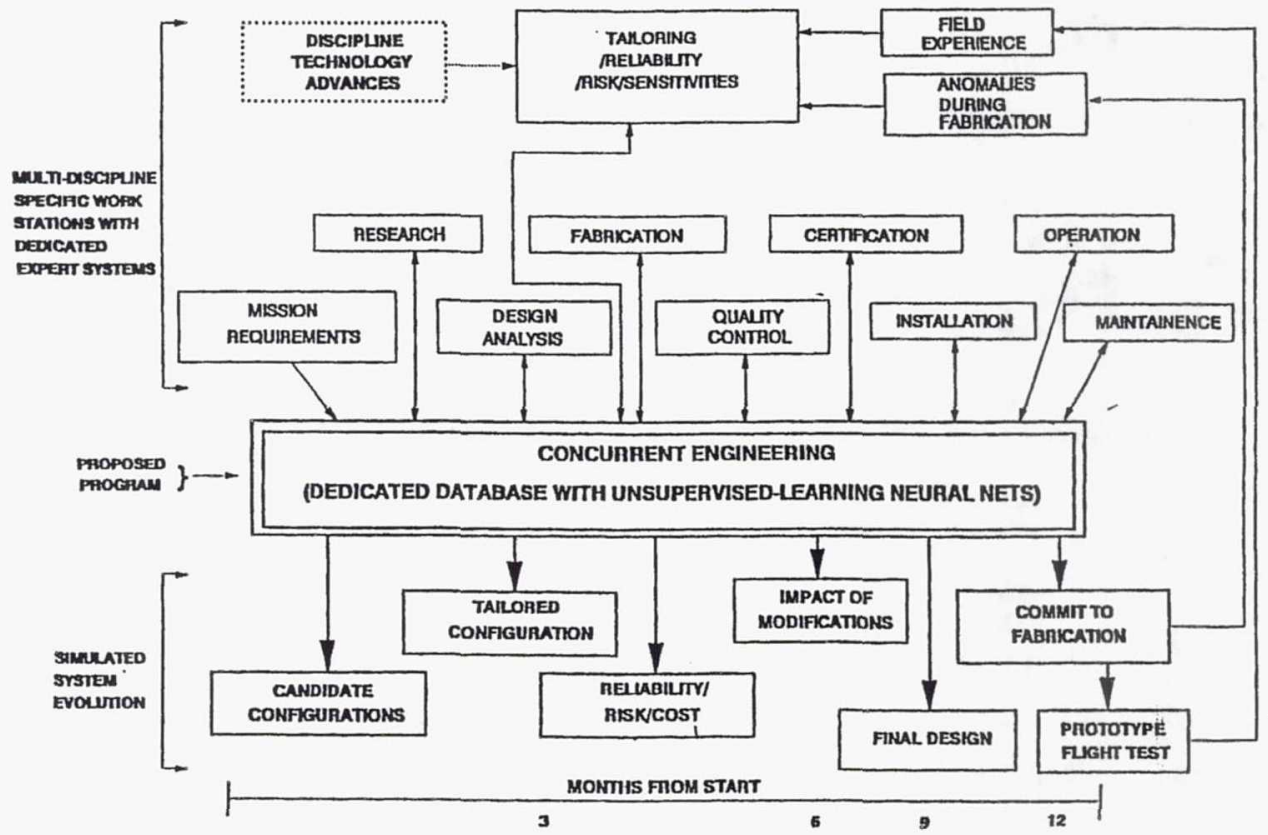


Public reporting burden for this collection of information is estimated to average 1 hour per response, including the time for reviewing instructions, searching existing data sources, gathering and maintaining the data needed, and completing and reviewing the collection of information. Send comments regarding this burden estimate or any other aspect of this collection of information, including suggestions for reducing this burden, to Washington Headquarters Services, Directorate for information Operations and Reports, 1215 Jefferson Davis Highway, Suite 1204, Arlington, VA 22202-4302, and to the Office of Management and Budget, Paperwork Reduction Project (0704-0188), Washington, DC 20503.

\begin{tabular}{|l|c|c|}
\hline 1. AGENCY USE ONLY (Leave blank) & $\begin{array}{c}\text { 2. REPORT DATE } \\
\text { February } 1993\end{array}$ & $\begin{array}{r}\text { 3. REPORT TYPE AND DATES COVERED } \\
\text { Technical Memorandum }\end{array}$
\end{tabular}

4. TITLE AND SUBTITLE

5. FUNDING NUMBERS

Computational Simulation for Concurrent Engineering of Aerospace

Propulsion Systems

6. AUTHOR(S)

WU-323-57-40

C.C. Chamis and S.N. Singhal

7. PERFORMING ORGANIZATION NAME(S) AND ADDRESS(ES)

8. PERFORMING ORGANIZATION

REPORT NUMBER

National Aeronautics and Space Administration

Lewis Research Center

Cleveland, Ohio 44135-3191

E-7592

9. SPONSORING/MONITORING AGENCY NAMES(S) AND ADDRESS(ES)

10. SPONSORING/MONITORING AGENCY REPORT NUMBER

National Aeronautics and Space Administration

Washington, D.C. 20546-0001

NASA TM-106029

\section{SUPPLEMENTARY NOTES}

Prepared for the 1992 American Institute of Aeronautics and Astronautics Aerospace Design Conference, Irvine, California, February 3-6, 1992.

C.C. Chamis, NASA Lewis Research Center, Cleveland, Ohio and S.N. Singhal, Sverdrup Technology, Inc., Lewis Research Center Group,

2001 Acrospace Parkway, Brook Park, Ohio 44142. Responsible person, C.C. Chamis, (216) 433-3252.

12a. DISTRIBUTION/AVAILABILITY STATEMENT

12b. DISTRIBUTION CODE

Unclassified - Unlimited

Subject Category 39

\section{ABSTRACT (Maximum 200 words)}

Results are summarized of an investigation to assess the infrastructure available and the technology readiness in order to develop computational simulation methods/software for concurrent engineering. These results demonstrate that development of computational simulation methods for concurrent engineering is timely. Extensive infrastructure, in terms of multi-discipline simulation, component-specific simulation, system simulators, fabrication process simulation, and simulation of uncertainties - fundamental to develop such methods, is available. An approach is recommended which can be used to develop computational simulation methods for concurrent engineering of propulsion systems and systems in general. Benefits and issues needing early attention in the development are outlined.

\section{SUBJECT TERMS}

15. NUMBER OF PAGES

Coupled multi-discipline; Structural tailoring; Damping; Icc impact; Acoustic fatiguc; Process tailoring; Component simulators; System simulators; Reliability; Risk; Fiber-composites; Blades; Turboprops; Engine structures; Propulsion systems; Quality control; Concurrent enginecring; Computational simulation; Fabrication; Uncertainties; Tiger teams

17. SECURITY CLASSIFICATION OF REPORT

Unclassified
18. SECURITY CLASSIFICATION OF THIS PAGE Unclassified
19. SECURITY CLASSIFICATION OF ABSTRACT Unclassified
22

16. PRICE CODE

$\mathrm{A} 03$ 
National Aeronautics and Space Administration

Lewis Research Center

Cleveland, Ohio 44135

Official Business

Penalty for Private Use $\$ 300$
FOURTH CLASS MAIL

ADDRESS CORRECTION REQUESTED

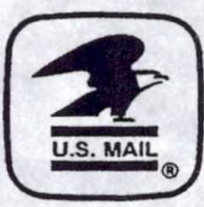

Postage and Fees Paid National Aeronautics anc Space Administration NASA 451 